Original Research Article

\title{
Investigation of anti-arthritic potential of Acacia torta (roxb.) craib
}

\author{
Girish N.*, Anil Kumar K. V., Beere Nagaraju
}

Department of Pharmacology, Visveswarapura Institute of Pharmaceutical Sciences, Bengaluru 560070, Karnataka, India

Received: 28 May 2017 Accepted: 24 June 2017

*Correspondence to:

Dr. Girish N.,

Email: girishn534@gmail.com

Copyright: (C) the author(s), publisher and licensee Medip Academy. This is an openaccess article distributed under the terms of the Creative Commons Attribution NonCommercial License, which permits unrestricted noncommercial use, distribution, and reproduction in any medium, provided the original work is properly cited.

\begin{abstract}
Background: Acacia torta (Roxb.) Craib, traditionally used in respiratory, circulatory, digestive, musculo-skeletal, skin diseases etc., Numerous plants of this genus have been used in folk medicine to treat stomach pain, cough, diarrhoea, piles, sore-throat; as astringent, antipyretic, antimicrobial, antimalarial, antiviral, anti-oxidant and as anti-hypertensive. Hence, the present study was aimed to investigate the anti-arthritic potential of Acacia Torta (Roxb.) Craib, since, systematic study of this plant has not been carried out.

Methods: Ethanol and water were used to prepare stem extract by soxhlet extraction method. The extract is evaluated by using Freund's complete adjuvant induced arthritis in albino wistar rats at the dose of $100 \mathrm{mg} / \mathrm{kg} / \mathrm{p}$.o. and $400 \mathrm{mg} / \mathrm{kg} / \mathrm{p} .0$. and indomethacin at $10 \mathrm{mg} / \mathrm{kg}$ were used for the study.

Results: The hydro alcoholic extract of the stem Acacia torta (Roxb.) Craib in crude form contains phytoconstituents like saponins, tannins, steroids, and triterpenes. The reference standard, Indomethacin at the dose of $10 \mathrm{mg} / \mathrm{kg}$ showed significant inhibition of paw edema by $71.61 \%$ ( $\mathrm{P}<0.001$ ), as compared to the vehicle control. Treatment with the hydro alcoholic extract of stem Acacia Torta at doses of 100 and $400 \mathrm{mg} / \mathrm{kg}$ caused significant inhibition of paw edema by $59.26 \%(\mathrm{P}<0.001)$ and $69.14 \%(\mathrm{P}<0.001)$ respectively, was observed on $21^{\text {st }}$ day, as compared to the vehicle control.

Conclusions: The data obtained from the present study indicated that several factors may contribute to the anti-inflammatory and anti-arthritic activity of hydro alcohol extract of the stem Acacia torta (Roxb.) Craib. adjuvant induced arthritis showed inhibition of prostaglandin synthesis might be the major mechanism by which the hydro alcoholic extract of the stem Acacia torta (Roxb.) Craib exerts anti-inflammatory and arthritic activity.
\end{abstract}

Keywords: Acacia Torta (Roxb.) Craib, Anti-arthritic, Freund's Adjuvant, Indomethacin, Paw edema, Prostaglandin

\section{INTRODUCTION}

Arthritis is a musculoskeletal disorder that destabilizes the normal coupling between degradation and regeneration of articular cartilage in joints following mechanical and a biological collapse in the body. This chronic disease is a chief cause of turmoil in the daily life of mankind throughout the globe. The pathophysiology of arthritis involves up-regulation of pro-inflammatory cytokines and over expression of pro-inflammatory enzymes, resulting in elevated levels of prostaglandins, leukotrienes and nitric oxide. ${ }^{1}$ Arthritis can affect individuals of any age, ranging from 25 to 50 years, predominantly among the geriatric population. There are about 100 types of arthritis of which the most commonly occurring include osteoarthritis, rheumatoid arthritis, ankylosing spondylitis, systemic lupus erythematous and juvenile arthritis. ${ }^{2}$

Though, the existing synthetic molecules have not been proven to provide satisfactory therapeutic management due to toxicity, side effects, drug resistance or recurrence of symptoms on discontinuation. ${ }^{3}$ Administration of these drugs is known to produce various unwanted effects including gastrointestinal disorders, immunodeficiency and humoral disturbances, cardiovascular complications etc. ${ }^{4}$ Moreover, the anti-arthritic drugs which inhibits the 
pro-inflammatory markers, like tumor necrosis factors (TNF- $\alpha$ ),interleukin-1 (IL-1) and interleukin-6 (IL-6) has life threatening side effects, and their long-term risk is not very much known, hence, limiting their clinical use for long-term basis. ${ }^{5}$

Hence, there is an urgent need to identify an alternative treatment options for arthritis. There is a continuous search for alternative; safe and effective anti arthritic agents is persisting especially from natural sources. ${ }^{6}$ Amongst the various experimental animal models of arthritis, complete Freund's adjuvant (CFA) induced poly-arthritis is one of the established methods which mimics the human pathophysiological state, including chronic swelling in multiple joints due to accumulation of inflammatory cells, joint cartilage erosion and bone destruction. CFA induces arthritis through altered leukocyte proliferation and differentiation, secretion of cytokines by mononuclear phagocytes, and transient activation and proliferation of CD41 lymphocytes. ${ }^{7}$

Acacia torta (Roxb.) Craib, an important medicinal plant, is commonly known as Aadaari, Lataa Khadira has traditionally used in cough, bronchitis, dysentery, tubercular fistula, measles, inflammation, sepsis (skin diseases) and in emmenagogue. ${ }^{8,9}$ The extract contains tannins, saponins, steroids, triterpenoids and alkaloids. It was observed that crude extract of Acacia Torta (Roxb.) Craib exert anti-inflammatory activity in rats. Several plants of this genus have been used in folk medicine to treat stomach pain, cough, diarrhoea, piles, sore-throat, as astringent, antipyretic, antimicrobial, antimalarial, antiviral, anti-oxidant, anti-hypertensive and as liver tonic. ${ }^{10,11}$ Acacia Torta (Roxb.) Craib has been traditionally used in Maharashtra, Kerala, Karnataka and in Himalayas for the treatment of inflammation and rheumatism. However, systematic study of this plant has not been carried out for the anti-inflammatory activity. Therefore, present study was undertaken to investigate anti-arthritic potential of stem of Acacia Torta (Roxb.) Craib bark extract against Freund's complete adjuvant induced arthritis in rats.

\section{METHODS}

\section{Plant material}

Acacia torta (Roxb.) Craib stem bark was selected for the present study. The plant belonging to family Mimosaceae was collected from the Savandurga state forest of Karnataka. The plants were authenticated by Dr. V. Rama Rao, Central Council for Research in Ayurvedic Sciences, Ministry of AYUSH, Govt. of India, G.C.P. Annexe, Ashoka Pillar, Jayanagar, Bengaluru.

\section{Preparation of extract}

The air dried and powdered stem of Acacia Torta (Roxb.) Craib were successively extracted with alcohol and water in a soxhlet apparatus.

\section{Preliminary phytochemical screening}

Qualitative phytochemical investigation of hydro alcoholic extract of stem Acacia torta was carried out using standard test of different phytochemicals e.g. alkaloids, glycosides, flavonoids etc.

\section{Animal care and maintenance}

Albino rats of either sex weighing between (150-200g) were procured from animal house of Visveswarapura Institute of Pharmaceutical Sciences, Bengaluru for experimental purpose. The animals were acclimatized to laboratory conditions for 7 days. The animals were supplied with commercially available standard diet. Water was allowed ad libitum under hygienic conditions. The animals were grouped in cages in an air conditioned room at the temperature of $22 \pm 1^{\circ} \mathrm{C}$ with $12 \mathrm{~h}$ light and dark cycle. The ethical guidelines for the investigation of the animals used in experiment were followed in all the tests.

\section{Acute oral toxicity studies}

The acute toxicity of stem extracts of Acacia torta (Roxb.) Craib was determined by using female albino rats of weight between (180-200)g, maintained under standard conditions. The animals were fasted for $12 \mathrm{hr}$ prior to the experiments. Animals were administered with single dose of stem extracts of Acacia torta (Roxb.) Craib and observed for its mortality up to $48 \mathrm{hr}$ study period (short term toxicity). Based on the short-term toxicity profile, the next dose was decided as per OECD guidelines No 423. From the LD50 dose 1/5th dose was selected and considered as high dose. ${ }^{12}$

\section{Experimental procedure $e^{13,14}$}

Albino Wistar rats of either sex weighing 150-200g were maintained in animal house and they were divided in to 4 groups of 6 animals each. They were acclimatized to housing conditions for at least one week prior to use. Prior to the experimentation they were acclimatized to housing conditions for at least one week period of time to adjust to the new environment providing with food and water and ad libitum. The experimental protocol was for twenty one days. Institutional animal Ethical Committee approval was obtained before carrying out this experiment.

- Group I: Control, animals were treated with $10 \%$ Tween-80 p.o

- $\quad$ Group II: Standard group, animals were treated with $10 \mathrm{mg} / \mathrm{kg}$ Indomethacin p.o for twenty one days.

- Group III: Animals were treated with $100 \mathrm{mg} / \mathrm{kg}$ b wt. p.o of hydro alcoholic extract of stem Acacia torta for twenty one days.

- $\quad$ Group IV: Animals were treated with $400 \mathrm{mg} / \mathrm{kg}$ b wt. p.o of hydro alcoholic extract of stem Acacia torta for twenty one days. 


\section{Induction of arthritis}

The experimental protocol was for 21 days and on day one, Arthritis was induced in all groups of rats by injecting $0.1 \mathrm{ml}$ Complete Freund's Adjuvant emulsion into the subplantar surface of right hind paw.

\section{Paw volume}

Measurement of paw volume was made on day $0,4,8,14$ and 21 using mercury plethysmograph. The percentage inhibition of oedema paw volume was evaluated, compared with vehicle control.

\section{Arthritic score}

The arthritis morphological feature of like redness, swelling and erythema 19, was monitored by set visual criteria as follows: normal paw $=0$, mild swelling and erythema of digits $=1$, swelling and erythema of the digits $=2$, severe swelling and erythema $=3$, gross deformity and inability to use the limb $=4$ on respective days.

\section{Statistical analysis}

Results were expressed as mean \pm SEM. Statistical significance was assessed using One-way and single measures of Analysis of variance (ANOVA) followed by Dunnett's comparison tests. ${ }^{* * *} \mathrm{P}<0.001$ and ${ }^{* *} \mathrm{P}<0.01$ was considered as significant Vs control.

\section{RESULTS}

\section{Acute oral toxicity study}

The acute toxicity studies reveal that the hydro alcoholic extract of stem Acacia torta (Roxb.) Craib were found to be non-toxic at dose of $2000 \mathrm{mg} / \mathrm{kg}$ and the extracts were found to be safe at dose of $2000 \mathrm{mg} / \mathrm{kg}$. Hence $2000 \mathrm{mg} / \mathrm{kg}$ was the maximum tolerable dose considered for the hydro alcoholic extract. Thereby the screening doses selected for systemic administration of test extracts for organ protective activities are:
- The hydro alcoholic extract of stem Acacia torta $100 \mathrm{mg} / \mathrm{kg}(1 / 20 \mathrm{th}$ of the $2000 \mathrm{mg})$

- The hydro alcoholic extract of stem Acacia torta $400 \mathrm{mg} / \mathrm{kg}(1 / 5 \mathrm{th}$ of the $2000 \mathrm{mg})$

\section{Adjuvant induced arthritis model in Albino Wistar rats}

As shown in Table 2 and Figure 1, the reference standard, Indomethacin at the dose of $10 \mathrm{mg} / \mathrm{kg}$ showed significant inhibition of paw edema by $71.61 \%$ (P <0.001), as compared to the vehicle control.

Table 1: Preliminary phytochemical screening.

\begin{tabular}{|ll|}
\hline Test & $\begin{array}{l}\text { Hydro alcoholic stem } \\
\text { extract }\end{array}$ \\
\hline Saponins & + \\
\hline Foam test & + \\
\hline Bromine water test & + \\
\hline Legal's test & + \\
\hline Tannins & + \\
\hline Ferric chloride test & + \\
\hline Gelatin test & \\
\hline Lead acetate test & + \\
\hline Steroids & + \\
\hline Libermann-Buchard test & \\
\hline Salkowski test & + \\
\hline Triterpenes & + \\
\hline Libermann-Buchard test & + \\
\hline Salkowski test & + \\
\hline Tschugajen test & \\
\hline Alkaloids & + \\
\hline Mayer's test & + \\
\hline Wagner's Test & + \\
\hline Hager's Test & - \\
\hline Flavonoids & $\mathbf{+}$ \\
\hline Ferric chloride test & +- NEGATIVE/ABSENT \\
\hline Lead acetate test & \\
\hline (+) POSITIVE/PRESENT & \\
\hline
\end{tabular}

Table 2: Effect of hydro alcoholic extract of Acacia torta (roxb.) craib stem in adjuvant induced arthritis model.

\begin{tabular}{|c|c|c|c|c|c|c|}
\hline \multirow{2}{*}{ Treatment } & \multicolumn{5}{|c|}{ Mean changes in paw oedema } & \multirow{2}{*}{$\begin{array}{l}\% \text { inhibition of paw } \\
\text { swelling on } 21^{\text {st }} \text { day }\end{array}$} \\
\hline & Day-0 & Day-4 & Day-7 & Day-14 & Day-21 & \\
\hline $\begin{array}{l}\text { Vehicle } \\
(10 \% \text { Tween-80) }\end{array}$ & $0.26 \pm 0.021$ & $0.73 \pm 0.021$ & $0.86 \pm 0.033$ & $0.86 \pm 0.033$ & $0.81 \pm 0.083$ & \\
\hline $\begin{array}{l}\text { Indomethacin } \\
(10 \mathrm{mg} / \mathrm{kg})\end{array}$ & $0.63 \pm 0.275^{\$}$ & $0.53 \pm 0.021^{* * *}$ & $0.4 \pm 0.025^{* * *}$ & $0.28 \pm 0.016^{* * *}$ & $0.23 \pm 0.015^{* * *}$ & $71.61 \%$ \\
\hline $\begin{array}{l}\text { Acacia Torta } \\
(100 \mathrm{mg} / \mathrm{kg})\end{array}$ & $0.3 \pm 0.025^{\$}$ & $0.55 \pm 0.022^{* *}$ & $0.61 \pm 0.030^{* * *}$ & $0.5 \pm 0.068^{* * *}$ & $0.33 \pm 0.069^{* * *}$ & $59.26 \%$ \\
\hline $\begin{array}{l}\text { Acacia Torta } \\
(400 \mathrm{mg} / \mathrm{kg})\end{array}$ & $0.36 \pm 0.061^{\$}$ & $0.56 \pm 0.210^{* *}$ & $0.53 \pm 0.061^{* * *}$ & $0.35 \pm 0.05^{* * *}$ & $0.25 \pm 0.047^{* * *}$ & $69.14 \%$ \\
\hline
\end{tabular}

Values are Mean \pm SEM, $\mathrm{P}$ value $* * \mathrm{P}<0.01, * * * \mathrm{P}<0.001$, \$ Not significant v/s Control. P-values were calculated by comparing with control by one way measures of ANOVA followed by Dunnett's test. 
Treatment with the hydro alcoholic extract of stem Acacia Torta at doses of 100 and $400 \mathrm{mg} / \mathrm{kg}$ caused significant inhibition of paw edema by $59.26 \%(\mathrm{P}<0.001)$ and $69.14 \%(\mathrm{P}<0.001)$ respectively, was observed on $21^{\text {st }}$ day, as compare to the vehicle control.

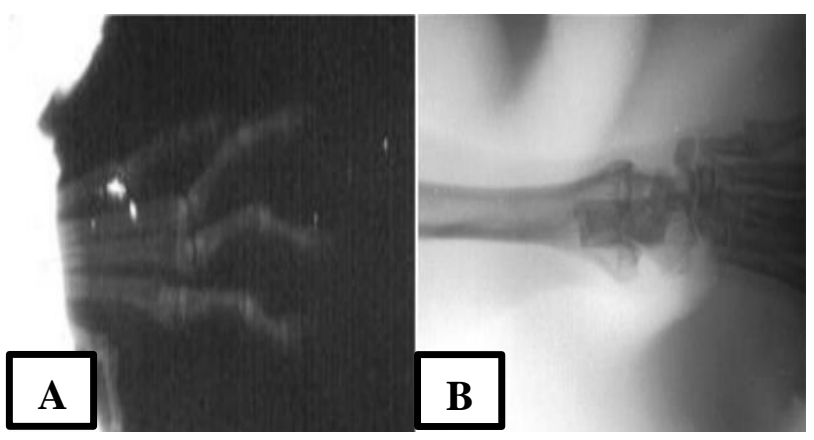

Figure 1 (A and B): X-Ray of normal rat paw: Normal joint space and articular region in $A$ and normal subchondral bone can be seen in $B$.

\section{Evaluation of early soft tissue and bone changes by conventional radiography}

There was a significant difference in the score between groups. By day 21 after sub plantar injection of FCA, swelling of soft tissue appeared in the control group. In the group treated with $100 \mathrm{mg}$ and $400 \mathrm{mg} / \mathrm{kg}$ of hydro alcoholic extract of stem Acacia torta there was a statistical and dose dependent reduction in swelling of soft tissue was observed. During the test period, the volume displaced by right hind paw with $100 \mathrm{mg}$ and $400 \mathrm{mg} / \mathrm{kg}$ of hydro alcoholic extract of stem Acacia torta was also measured, and it was respectively $0.33 \pm 0.069$ and $0.25 \pm 0.047$ as compared to vehicle control. The characteristics changes observed in radiography were as mentioned below and scoring was done accordingly.

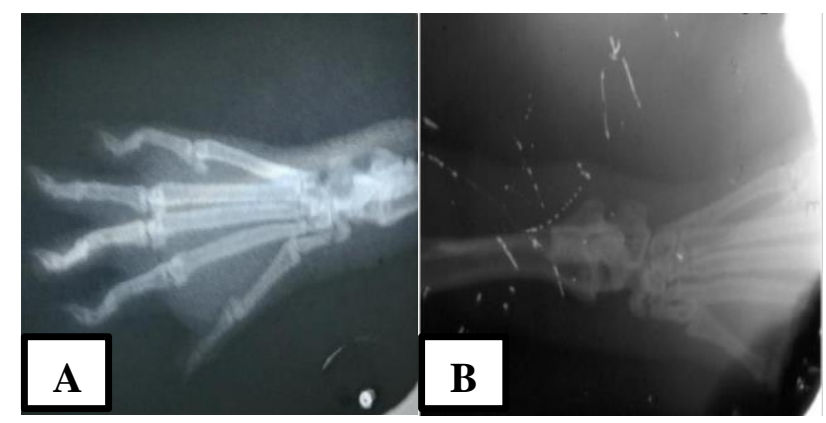

Figure 2 (A and B): X-Ray of 10\% tween-80 treated group after 21 days of Adjuvant injection: Absence of joint space (scoring is ' ++++ ') in A and sub-chondral sclerosis (scoring is ' ++++ '); sub-chondral cysts (scoring is '+') and osteophytes (scoring is ' + ') in B.

\section{DISCUSSION}

Most of the investigators have reported that inhibition of adjuvant induced arthritis in rats is one of the most suitable test procedures to screen anti-arthritic agents since it closely resembles human arthritis. ${ }^{15}$

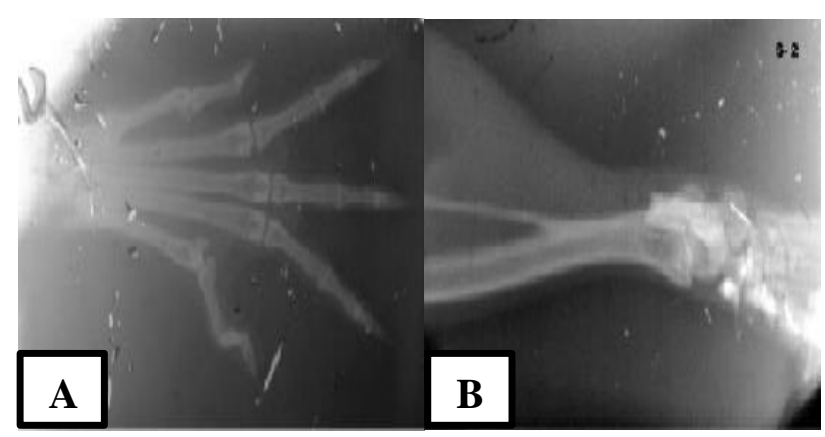

Figure 3 (A and B): X-Ray of Indomethacin (10mg/kg) treated group after 21 days of Adjuvant injection: Reduced joint space (scoring is ' ++ ') and irregular articular margin (scoring is ' ++ ') in $\mathrm{A}$ and subchondral sclerosis (scoring is ' +++ ') and sub-chondral cysts (scoring is ' + ') can be seen $B$.

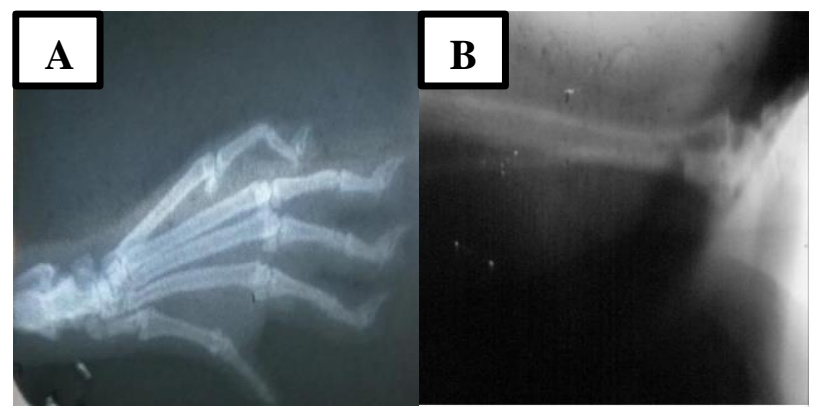

Figure 4 (A and B): X-Ray of extract of root Acacia Torta $(100 \mathrm{mg} / \mathrm{kg})$ treated group after 21 days of Adjuvant injection: Reduced joint space (scoring is ' ++ ') and irregular articular margin (scoring is ' ++ ') in Age and sub-chondral sclerosis (scoring is ' +++ ') and sub-chondral cysts (scoring is ' ++ ') in $\mathbf{B}$.

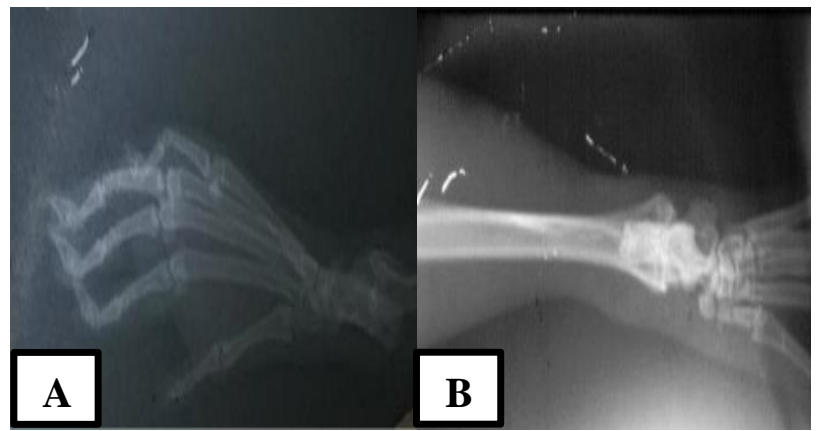

Figure 5 (A and B): X-Ray of extract of root Acacia Torta $(400 \mathrm{mg} / \mathrm{kg})$ treated group after 21 days of Adjuvant injection: Reduced joint space (scoring is ' ++ ') and irregular articular margin (scoring is ' ++ ') in $A$ and sub-chondral sclerosis (scoring is ' ++ ') and sub-chondral cysts (scoring is ' ++ ') in $\mathbf{B}$.

Paw swelling is one of the major factors in assessing the degree of inflammation and curative efficacy of drugs. ${ }^{16}$ 
Injection of CFA sub plantar into hind paw of rats produces localized inflammation and an immediate swelling (primary inflammation) was produced which is followed by secondary inflammation after 8-12 days. ${ }^{17}$ Bacterial peptidoglycan and muramyl dipeptide are responsible for its induction. ${ }^{18}$ It occurs through cell mediated-autoimmunity by structural mimicry between mycobacteria and cartilage proteoglycans in rats. ${ }^{19}$ Standard indomethacin and extract of stem Acacia torta (Roxb.) Craib significantly suppressed the second phase of CFA induced inflammation.

Conventional radiography is still an important tool commonly used for the detection and quantification of destruction in arthritis. The ability to identify early changes in rheumatoid arthritis or other inflammatory joint disease is crucial for both the prognosis and treatment strategy. It has been demonstrated that early treatment significantly delays joint destruction. In addition, the bone changes in animal model of rheumatoid arthritis are usually too minute to be clearly assessed by conventional radiography. In the group treated with hydro alcoholic extract of stem Acacia torta (Roxb.) Craib and indomethacin, dose dependent reduction in swelling of soft tissue, reduced joint space, correction of irregular articular margin and normalisation of sub-chondral sclerosis was observed. ${ }^{20}$

\section{CONCLUSION}

The data obtained from the present study indicated that several factors may contribute to the anti-inflammatory and anti-arthritic activity of hydro alcohol extract of the stem Acacia torta (Roxb.) Craib. Adjuvant induced arthritis showed inhibition of prostaglandin synthesis might be the major mechanism by which the hydro alcoholic extract of the stem Acacia torta (Roxb.) Craib exerts anti-inflammatory and anti-arthritic activity.

Funding: No funding sources

Conflict of interest: None declared

Ethical approval: The study was approved by the Institutional Ethics Committee

\section{REFERENCES}

1. Meyer DM, Jesson MI, Li X, Elrick MM, Shippy CLF, Warner JD, et al. Anti-inflammatory activity and neutrophil reductions mediated by the JAK1/JAK3 inhibitor, CP-690,550 in rat adjuvant-induced arthritis, Journal of Inflammation. 2010;7(41):112-6.

2. Bang JS, Oh DH, Choi HM. Anti-inflammatory and antiarthritic effects of piperine in human interleukin 1stimulated fibroblast-like synoviocytes and in rat arthritis models. Arthritis Research and Therapy. 2009;11(2):1-9.

3. Bansod MS, Kagathara VG, Pujari RR, Patel VB, Ardeshna HH. Therapeutic effect of a poly-herbal preparation on adjuvant induced arthritis in wistar rats,
International Journal of Pharmacy and Pharmaceutical Sciences. 2011;3(2):186-92.

4. Ahmed S, Anuutiyo J, Malemud CJ, Haqqi TM. Biological basis for the use of botanicals in osteoarthritis and rheumatoid arthritis: a review, Evidence-Based Complementary and Alternative Medicine. 2005;2(1):301-8.

5. Thite AT, Patil R, Naik SR. Anti-arthritic activity profile of methanolic extract of Ficus bengalensis: Comparison with some clinically effective drugs, Biomedicine \& Aging Pathology. 2014;3(4):207-17.

6. Koli C, Akah PA, Nwafor S. Anti-inflammatory activity of plants, Journal of Natural Remedies. 2003;3(1):1-30.

7. Singh S, Majumder DK. Effect of fixed oil of Ocimum sanctum against experimentally induced arthritis and joint edema in laboratory animals, Pharmaceutical Biology. 1996;34(3):218-22.

8. Bokhad MN, Rothe SP. An Overview of Medicinally Important Lianas from Dry Deciduous Forest of West vidarbha Region (M.S) India. Bioscience Discovery. 2015;6(2):117-20.

9. Girish N, Kumar AKV, Nagaraju B. Evaluation of anti-inflammatory activity of Acacia torta (Roxb.) Craib. International Journal of Experimental Pharmacology. 2017;7(2):39-42.

10. Girish N, Kumar AKV, Nagaraju B. Screening of antiinflammatory activity of Acacia torta (Roxb.) Craib using cotton pellet induced granuloma. International Journal of Preclinical and Pharmaceutical Research. 2017;8(2):40-3.

11. Mohammad R, Shariq S, Roohi Z, Malik I. Bark of Acacia Arabica-A Nature's Gift: An Overview. Int. Res J. Med Sci. 2014;2(5):20-4.

12. OECD/OCDE 423-OECD guideline for testing of chemicals-Acute Oral Toxicity; Acute Toxic Class Method. Adopted: 17th December 2001. Available at: https://ntp.niehs.nih.gov/iccvam/suppdocs/feddocs/oe cd/oecd_gl423.pdf

13. Jubie S, Jawahar N, Koshy R, Gowramma B, Murugan V, Suresh B. Anti-arthritic activity of bark extracts of Alangiumsalviifoliumwang. Rasayan J. Chem. 2008;1:433-6.

14. Rajaram C, Reddy RK, Chandra Sekhar K. Evaluation of anti-arthritic activity of Caesalpiniapulcherrimain freund's complete adjuvant induced arthritic rat model. J. Young Pharmacists. 2015;7(2).

15. Chatterjee S, Das SN. Anti-inflammatory effect of a poly-herbal drug \& its mechanism of action. Indian J. Pharmacol. 1996;28:116-9.

16. Begum VH, Sadique J. Long term effect of herbal drug Withaniasomnifera on adjuvant induced arthritis in rats. Indian J Exp Biol. 1988;26:877-82.

17. Watnick AS, Sabin C. The effect of clonixin and betamethasone on adjuvant induced arthritis and experimental allergic encephalomyelitis in rats. Japan J. Pharmacol. 1972;22:741-8.

18. Crofford LJ, Sano H, Karalis K, Webster EL, Goldmuntz EA, Chrousos GP, et al. Local secretion of corticotropin-releasing hormone in the joints of Lewis 
rats with inflammatory arthritis. J. Clin. Invest. 1992;90:2555-64.

19. Vijayalakshmi T, Muthulakshmi V, Sachdanandam P. Salubrious effect of Semecarpusanacardium against lipid peroxidative changes in adjuvant arthritis studied in rats. Mol. Cell Biochem. 1997;175:65-9.
20. Gureyev TE, Stevenson AW, Paganin D, Mayo SC, Pogany A. Quantitative methods in phasecontrast Xray imaging. J Digit Imaging. 2000;13:121-6.

Cite this article as: Girish N, Kumar AKV, Nagaraju B. Investigation of anti-arthritic potential of Acacia torta (roxb.) craib. Int J Basic Clin Pharmacol 2017;6:1981-6. 